\title{
Spontaneous Neuronal Calcium Spikes and Waves during Early Differentiation
}

\author{
Xiaonan Gu, Eric C. Olson, and Nicholas C. Spitzer \\ Department of Biology and Center for Molecular Genetics, University of California at San Diego, La Jolla, California \\ 92093-0357
}

Calcium ions play critical roles in neuronal development, but the factors that govern spontaneous fluctuations in intracellular calcium are not well understood. Transient, repeated elevations of calcium in embryonic Xenopus spinal neurons have been recorded over periods of $1 \mathrm{hr}$ in vitro and in vivo, confocally imaging fluo-3-loaded cells at 5 sec intervals. Calcium spikes and calcium waves are found both in neurons in culture and in the intact spinal cord. Spikes rise rapidly to $\sim \mathbf{4 0 0} \%$ of baseline fluorescence and have a characteristic double exponential decay, while waves rise slowly to $\sim 200 \%$ of baseline fluorescence and decay slowly as well. Imaging of fura-2-loaded neurons indicates that intracellular calcium increases from 50 to $500 \mathrm{~nm}$ during spikes. Both spikes and waves are abolished by removal of extracellular calcium. Developmentally, the incidence and frequency of spikes decrease while the incidence and frequency of waves are constant.

Spikes are generated by spontaneous calcium-dependent action potentials that can be triggered by low-threshold, T-type calcium current and are eliminated by agents that block voltage-dependent calcium channels. They can be elicited by depolarization, are generated in an all-or-none manner, and are rapidly and bidirectionally propagated. Spikes also utilize intracellular calcium stores, since blocking release from stores substantially reduces their amplitude. Waves are not elicited by depolarization nor by activation of glutamate receptors, and are propagated at a rate consistent with diffusion of calcium. Waves are blocked by $\mathrm{Ni}^{2+}$ at a higher concentration than required to block classical voltage-dependent calcium channels. Previous work now suggests that spikes are required for expression of the transmitter GABA and for potassium channel modulation. The present study indicates that waves in growth cones are likely to regulate neurite extension.

[Key words: calcium imaging, spinal neurons, spontaneous activity, neuronal differentiation, confocal imaging in vivo, calcium stores, calcium spikes, calcium waves]

\footnotetext{
Received Feb. 7, 1994; revised Apr. 18, 1994; accepted May 5, 1994.

We thank D. Gurantz, S. R. Lockery, and A. B. Ribera for comments on the manuscript, and $S$. Watt and I. Hsieh for technical assistance. We acknowledge grant support from NIH NSI5918.

Correspondence should be addressed to Nicholas C. Spitzer, Department of Biology, 0357, University of California, San Diego, 9500 Gilman Drive, La Jolla, CA 92093-0357.

Copyright (C) 1994 Society for Neuroscience $0270-6474 / 94 / 146325-11 \$ 05.00 / 0$
}

Calcium influx is an important determinant of synaptic plasticity in the mature nervous system (Bekkers and Stevens, 1990; Malinow and Tsien, 1990; Guthrie et al., 1991; Müller and Connor, 1991). Understanding the mechanisms by which calcium is elevated has provided insights into the basis of changes in synaptic efficacy. During development, calcium influx can regulate neuronal migration (Komuro and Rakic, 1992, 1993), pattern formation (Constantine-Paton et al., 1990; Shatz, 1990; Yuste et al., 1992), stabilization of transmitter phenotype (Nishi and Berg, 1981; Walicke and Patterson, 1981), and neurite extension (Mattson and Kater, 1987). Thus, the mechanisms by which intracellular calcium is normally elevated spontaneously in differentiating ncurons are of interest.

Normal differentiation of embryonic amphibian spinal neurons requires extracellular calcium during an early period. Cells dissociated from the neural plate differentiate morphologically $6 \mathrm{hr}$ after plating in culture and exhibit calcium-dependent action potentials (Spitzer and Lamborghini, 1976). Further differentiation of these young neurons is most sensitive to calcium for the following 6-12 hr in vitro. By 18-24 hr in culture, mature neurons exhibit brief action potentials that are largely sodium dependent. Removal of extracellular calcium or blockade of calcium channels during this calcium-sensitive period alters their morphology, sensitivity to transmitters, synapse formation, channel modulation, and neurotransmitter expression (Bixby and Spitzer, 1984a; Henderson et al., 1984; Holliday and Spitzer, 1990, 1993; Desarmenien and Spitzer, 1991; Spitzer et al., 1993). Moreover, calcium-induced calcium release is necessary for normal neurite extension and expression of ncurotransmitter (Holliday et al., 1991). These results suggest that calcium influx and calcium release from stores are required for normal differentiation, and imply that these processes occur naturally during development.

Spontaneous transient elevations of intracellular calcium have been observed in cultured embryonic spinal neurons during the calcium-sensitive period, using the ratiometric calcium indicator fura-2AM (Holliday and Spitzer, 1990). These calcium transients were suppressed by removal of extracellular calcium or block of high-voltage-activated calcium current. Moreover, low-voltage-activated calcium current appeared to be involved in depolarizing cells and triggering calcium transients ( $\mathrm{Gu}$ and Spitzer, 1993b). During this period no changes in steady state concentrations of calcium were recorded, although depolarization with high $\mathrm{KCl}$ sufficient to activate voltage-dependent calcium channels increased intracellular calcium (Holliday and Spitzer, 1990). However, previous investigation of calcium el- 
evations in embryonic Xenopus spinal neurons has been restricted to brief periods of examination.

In the present study, we have monitored changes in intracellular calcium in vitro and in vivo over an extended period to investigate the types of spontaneous calcium fluctuations that occur, as well as their incidence and frequency. We have studied the way in which they change during development, and the mechanisms by which they are generated. Moreover, we have assessed the functions they may play in regulating neuronal differentiation. Imaging fluo-3AM-loaded neurons with confocal microscopy has enabled analysis of spontaneous elevations of calcium occurring over periods of $1 \mathrm{hr}$. Embryonic spinal neurons exhibit distinct signatures of spontaneous elevation of intracellular calcium when they are undergoing primary differentiation, both in culture and in the intact spinal cord. Based on kinetic properties, these fluctuations are distinguished as two types of activity: fast calcium spikes and slow calcium waves. They differ further with respect to their regulation during development and the mechanisms by which they are generated. Spikes and waves appear to be required for separate aspects of neuronal differentiation.

Preliminary accounts of some of these findings have appeared (Gu et al., 1992; Gu and Spitzer, 1993a).

\section{Materials and Methods}

Cultures and spinal cords. Many features of preparation of cultures, spinal cords, and imaging procedures have been described (Holliday et al., 1991; Desarmenien et al., 1993; Gu and Spitzer, 1993b). Cultures were prepared from embryos of Xenopus laevis at the neural plate stage (stage 15; Nieuwkoop and Faber, 1967). Tissue from the posterior presumptive spinal cord region was dissected and treated with collagenase B $(1 \mathrm{mg} / \mathrm{ml}$; Sigma) in low-calcium medium (mM: $58.8 \mathrm{NaCl}, 0.67 \mathrm{KCl}$, $0.5 \mathrm{CaCl}_{2}, 8 \mathrm{~mm}$ HEPES, pH adjusted to 7.8 with $\mathrm{NaOH}$ ) for 5-15 min. Ectoderm was thus separable from mesoderm, endoderm, and notochord; ectodermal cells, including neural folds, were dissociated in divalent cation-free medium (in mM: $58.8 \mathrm{NaCl}, 0.67 \mathrm{KCl}, 0.4$ EDTA, 4.6 Tris, $\mathrm{pH}$ adjusted to 7.8 with $\mathrm{HCl}$ ) and plated on $35 \mathrm{~mm}$ tissue culture dishes (Costar). These neuron-enriched cultures contain neurons and many non-neuronal cells but are free of myocytes; cells are present at low density, and neurons constitute only $3 \%$ of the total cell population (Holliday and Spitzer, 1993). Neurons at 6-8 hr in vitro are referred to as young and neurons at $17-22 \mathrm{hr}$ are termed mature. Spinal cords were prepared from embryos at neural tube stages (stages 18-30), overlapping the period studied in culture. Tissue from the posterior spinal cord region was dissected and treated with collagenase B in lowcalcium medium for 5-15 min, as for cultures. The intact spinal cord was then separated from mesoderm, endoderm, and notochord and pinned ventral surface up on $35 \mathrm{~mm}$ tissue culture dishes coated with Sylgard (Dow Corning). The same medium was used both for cultures and for spinal cords, containing (in $\mathrm{mm}$ ) $58.8 \mathrm{NaCl}, 0.67 \mathrm{KCl}, 1.31$ $\mathrm{MgSO}_{4}, 10 \mathrm{CaCl}_{2}$, and 4.6 Tris; $\mathrm{pH}$ was adjusted to 7.8 with $\mathrm{HCl}$.

Imaging. For calcium imaging in vitro and in vivo, cells in culture or freshly dissected whole spinal cords were incubated for $30 \mathrm{~min}$ with the fluorescent calcium indicator fluo-3AM (Molecular Probes) in most experiments. The dye was dissolved in DMSO $(50 \mu \mathrm{g} / 10 \mathrm{ml}$; Sigma) and added to achieve a final concentration of $2 \mu \mathrm{M}$. Free dye was washed out with three rinses of culture medium over a $30 \mathrm{~min}$ period. This dye is useful for measurement of transient signals at relatively low levels of illumination, allowing signal acquisition over long periods without photodynamic damage to cells. Imaging of dye-loaded cultured cells or spinal cords for periods of $1 \mathrm{hr}$ was achieved with a Bio-Rad MRC600 argon laser confocal system with a Zeiss microscope and a $20 \times$ waterimmersion objective. Images were collected at 5 sec intervals; individual cells were illuminated for $<0.2 \mathrm{sec}$. Confocal line scans at $4 \mathrm{msec}$ sweep were used to measure rapid changes in fluorescence along a single axis. Sweeps were displayed horizontally in a raster array. Each image was held on a video monitor until acquisition of the subsequent image that replaced it. Images from the monitor were continuously recorded to standard VHS videotape on both regular and time-lapse VCRs, or an- alyzed on line. Imaging of cultured cells was also carried out with an SIT camera (SIT 68, MTI) mounted on a Zeiss Photoscope and a Hamamatsu Photonics image processing system (C1966) with a resolution of $640 \times 483 \times 16$ bits, for periods no longer than $6 \mathrm{~min}$ in duration. Images were acquired continuously and written to videotape with 33 $\mathrm{Hz}$ time resolution. SIT cameras exhibit signal retention that is greater at dimmer illumination. This effect could produce an overestimatc of rise and decay times analyzed from data acquired in this manner. The similarity of results from two different instruments and procedures reduces the likelihood of artifacts in these measurements. Quantitative comparisons of fluo-3 fluorescence in the present study were made only for nucleus versus cytoplasm, and spike versus wave amplitude. In the former case, the higher nuclear elevation replicated previous results from confocal line scan analysis (Holliday et al., 1991). In the latter case, when cell bodies were evenly loaded and sampled over the same region, spikes produced greater elevations of fluorescence than waves both in individual cells and across the population.

Fura-2AM (Molecular Probes) was used in some experiments to ratiometrically estimate intracellular calcium concentrations. Dye was dissolved in DMSO and added to cultures to achieve a final concentration of $2 \mu \mathrm{M}$. Fluorescence emission at $500 \mathrm{~nm}$ was elicited by excitation at 340 and $380 \mathrm{~nm}$ and imaged with the Photoscope and SIT camera. Images were acquired continuously and either captured and saved on the computer at $20 \mathrm{~Hz}$ or written to VHS tapes at $33 \mathrm{~Hz}$. Identical equipment and optical settings were used for calibrations and for experiments.

Data analysis. The impact of imaging on cell survival was assessed by comparing counts of cells in imaged fields at the time of imaging and $1 \mathrm{~d}$ later; adjacent fields in the same cultures served as controls. Four cultures were scored, with $\geq 50$ neurons/field. The effect of loading cells with fluo-3AM was evaluated in a similar manner.

Fluorescent pixel intensities of regions of neurons in each image were analyzed with the IMAGE program (W. Rasband, NIH), either on line or by replay of tapes using a QuickCapture frame grabber board (Data Translation). Intensities were digitally averaged with a Macintosh IIci computer. Changes in fluorescence intensity of each neuron were normalized to its baseline fluorescent intensity. Results from on-line and videotape analysis were not different. Spike and wave activities were scored as events exceeding $150 \%$ of baseline, and distinguished on the basis of their kinetics. Each spike and wave was reconfirmed by visual examination of time-lapse videotapes, to avoid analysis of spurious signals arising from cell movements or neighboring cells. The relative fluorescence change of fluo-3 over the range of interest is proportional to the actual concentration of intracellular calcium (Kao et al., 1989; Cornell-Bell et al., 1990; Holliday and Spitzer, 1990). Spike rise time in fluo-3-loaded cells was measured from digitized data as the interval between initiation point and peak. Time constants of spike decay were determined by fitting curves with single or double exponentials using the AXOGRAPH program (Axon Instruments). Digitized intensity values from 4-36 fura-2-imaged frames were averaged to enhance the signal to noise for calibration and for measurement of resting calcium levels. The intracellular calcium concentration was estimated from the ratio image, using the equation $\left[\mathrm{Ca}^{2+}\right]=K_{D}\left(\left(R-R_{\min }\right) /\left(R_{\max }-R\right)\right) F_{0} / F_{s^{*}} \cdot F_{0}$ and $F_{s}$ are fluorescence intensities at $380 \mathrm{~nm}$ in 0 and saturating [ $\mathrm{Ca}^{2+}$ ]. $R_{\min }$ and $R_{\max }$ are ratios of fluorescence excited at 340 and $380 \mathrm{~nm}$ under experimental conditions of 0 and saturating $\left[\mathrm{Ca}^{2+}\right] . K_{D}$ is $135 \mathrm{nM}$ (Grynkiewicz et al., 1985). Calibration entailed examination of fura-2-loaded cells permeabilized with $5 \mu \mathrm{M}$ ionomycin for $30 \mathrm{~min}$ and either incubated in $10 \mathrm{mM} \mathrm{Ca}^{2+}$ to yield $R_{\max }$ and $F_{s}$, or incubated in $0 \mathrm{mM} \mathrm{Ca}^{2+}$ plus 2 mM EGTA and $2 \mathrm{mM} \mathrm{Mn}^{2+}$ to yield $R_{\min }$ and $F_{o}$ (Grynkiewicz et al., 1985; Holliday and Spitzer, 1990). All average values of data were compiled as mean $\pm \mathrm{SEM}$ for the number of cells indicated.

Extracellular stimulation. Action potentials were stimulated with extracellular electrodes of tungsten wire, sharpened to 10-20 $\mu \mathrm{m}$, coated with $\mathrm{AgCl}$, and placed 5-10 $\mu \mathrm{m}$ from the soma or growth cone of fluo3-or fura-2-loaded neurons (Grumbacher-Reinert and Nicholls, 1992). Stimulation pulses were $4-12 \mathrm{~V}$ with $0.1 \mathrm{msec}$ duration. Stimuli applied at $>40 \mu \mathrm{m}$ from the cell were ineffective even at $15 \mathrm{~V}$. Spikes elicited in response to pairs of pulses delivered at 5 min intervals were the same at a $250 \mathrm{~Hz}$ image acquisition rate for fluo-3-loaded cells, since they are produced in an all-or-none manner (see Results). Accordingly, pairs of stimuli were used to examine responses to excitation of fura-2-loaded neurons at 340 and $380 \mathrm{~nm}$ to generate ratio values at high time resolution. When caffeine was used to evaluate the contribution of stores, the initial elevation of $\left[\mathrm{Ca}^{2+}\right]_{i}$ following application was allowed to 
return to baseline prior to stimulation (Holliday et al., 1991). During stimulation, changes in fluorescence intensity were imaged confocally or with Photoscope and SIT camera and data were stored on computer or VHS tapes.

Probability estimates. Cells were considered coactive when they initiated spikes within the same $5 \mathrm{sec}$ interval on multiple occasions. For $m$ spiking cells, the random probability that $n$ cells were coactive $i$ times was calculated as follows: the probability of first firing is approximated by $P_{1}=C\{i /(720)\}^{n} \times 720$. The probability of the second instance of coactivity changes, since the number of possibilities is diminished by one and the group of coactive cells is fixed. Thus, the probability of the second firing is approximated by $P_{2}=\{(i-1) /(720-1)\}^{n} \times(720-$ $1)$. For the $i$ th instance of coactivity, the probability becomes $P_{i}=\{i$ $-(i-1) /(720-(i-1))\}^{n} \times(720-(i-1))$. The random probability for $n$ cells to be coactive $i$ times is then calculated as a cumulative probability, $P=P_{1} \times P_{2} \times \ldots \times P_{i}$. This calculation provides only a rough estimate, since the timing of each event during the period sampled influences the probability of later events. Moreover, it yields an overestimate since it generates extra counts of coactivity of the specified number of cells from instances in which a larger number of cells are coactive. This error depends on $(m-n)$; when $m$ is small, as in culture $(m \sim 5)$, the approximation is good. Although imprecise, this calculation provides a quantitative evaluation of the random probability of coactivity.

Modeling. Details of computer modeling of action potentials have been described (Lockery and Spitzer, 1992; Gu and Spitzer, 1993b). Neuronal currents were reconstructed with simplified Hodgkin-Huxley equations, choosing parameters specifying conductance, steady state activation and inactivation, and time constants for each current. Calcium dynamics were defined by a compartmental model in which intracellular submembrane calcium is supplied by calcium currents and removed by diffusion to an interior compartment. Action potentials were simulated under conditions of $10 \mathrm{~mm}$ external calcium, to be comparable with the calcium concentration in culture medium. Action potential thresholds were evaluated with the inclusion of all currents and with the systematic elimination of inward currents.

\section{Results}

Spontaneous spikes and waves in cultured embryonic neurons

Previous work demonstrated that influx of calcium during a sensitive period is required for normal neuronal development. To investigate the mechanisms of calcium influx, its developmental regulation, and its functions, we analyzed the characteristics of transient elevations of intracellular calcium $\left(\left[\mathrm{Ca}^{2+}\right]_{i}\right)$. Spontaneous calcium transients in embryonic spinal neurons were revealed by acquisition of confocal fluorescence images at $5 \mathrm{sec}$ intervals for $1 \mathrm{hr}$ periods, using the calcium indicator fluo3. Changes in fluorescence intensity in the cell body and growth cones were digitally analyzed from each of 720 images. Cells were exposed to laser illumination for $<0.2 \mathrm{sec}$ for each image $(<2.4 \mathrm{~min}$ exposure/hr). This procedure enabled examination of changes in $\left[\mathrm{Ca}^{2+}\right]_{i}$ over an extended time without detectable photodynamic damage to dye-loaded cells. More than $95 \%$ of neurons in culture developed normally by morphological criteria by $12 \mathrm{hr}$ after imaging compared to unimaged controls; moreover, neurite initiation and extension occurred during imaging. Counts of all cells in imaged fields $1 \mathrm{~d}$ later indicated that this procedure did not promote cell death $(86 \pm 3 \%$ vs $85 \pm$ $5 \%$ survival). Similarly, there was no detectable effect on survival of loading cells with fluo-3AM.

At the onset of the calcium-sensitive period, two distinct types of spontaneous elevations of $\left[\mathrm{Ca}^{3+}\right]_{i}$ wcrc found in ncurons differentiating in culture and in the intact embryonic spinal cord (see below). Fast calcium spikes exhibited a rapid, stereotyped rise and decay in fluorescence intensity (Fig. $1 A$ top, $B$ ). Digitally analyzed data from neuronal cell bodies in vitro showed that all spikes reached their peaks in $<5 \mathrm{sec}$. A double exponential described their decay in $>80 \%$ spikes, with time constants of $11 \pm 1 \mathrm{sec}$ and $2.9 \pm 0.2 \mathrm{~min}(n=12)$. The remainder, which were typically of smaller amplitude, exhibited only the fast time constant ( $11 \pm 2 \mathrm{sec} ; n=5$ ). Spikes were propagated throughout the full extent of single neurons within a $5 \mathrm{sec}$ interval. Their amplitudes ranged from $150 \%$ to $900 \%$ of baseline intensity with an average increase of $375 \pm 30 \%$ in the soma $(n=57)$. The mean incidence of spikes examined over $10 \mathrm{~min}$ intervals was relatively evenly distributed throughout the $1 \mathrm{hr}$ period.

In contrast, slow calcium waves in the cell body did not exhibit uniform rise and decay, and displayed a gradual increase in fluorescence intensity requiring $>30 \mathrm{sec}$ followed by a decay over several minutes or longer (Fig. $1 A$ bottom, $B$ ). Further, waves initiated in the soma in most cases did not spread into the neurites. Their amplitudes ranged from $150 \%$ to $600 \%$ of baseline intensity with average values of $175 \pm 5 \%$ in the soma $(n=57)$. Waves also exhibited roughly evenly distributed incidence over $15 \mathrm{~min}$ intervals throughout the $1 \mathrm{hr}$ period. A single neuron could generate both spikes and waves (Fig. $1 B$ ).

If spikes and waves transduce the signals of the calciumsensitive period, their generation would be expected to depend upon extracellular calcium. Both spikes and waves in cultured neurons were eliminated by replacing extracellular calcium with magnesium plus $1 \mathrm{~mm}$ EGTA (Table 1), suggesting that calcium influx is involved in both activities. In culture, spikes and waves were observed with the same incidence and frequency in morphologically differentiated neurons and in cells which have no neurites when imaged, but differentiate into neurons during or after imaging. However, waves were also seen in unidentified cells. The mechanisms by which they are produced may be different, since waves in some unidentified cells can persist when extracellular calcium is removed. The neuronal specificity of spikes makes them an early marker of neuronal differentiation.

Given the developmental role for calcium signaling, spike and wave activities were examined at early and late times in culture. Among 80 young neurons examined in 6-8 hr cultures, 69\% were active during the $1 \mathrm{hr}$ period of imaging. Spikes or spikes and waves were produced in $35 \%$ of cells, while $34 \%$ generated waves alone (Table 1). Spikes or spikes and waves occurred one to seven times per hour in the cell body, while waves alone occurred one to four times per hour, with average frequencies of $2.4 \pm 0.3$ and $2.1 \pm 0.2 / \mathrm{hr}(n=27)$. The incidence and frequency of spikes and waves were highest during this period of development in vitro. Spike incidence decreased to $19 \%$ among 85 mature neurons examined in $17-22 \mathrm{hr}$ cultures, and the average frequency dropped to $1.6 \pm 0.2 / \mathrm{hr}(n=16)$. In contrast, the incidence and frequency of waves were relatively constant between young and mature neurons $(38 \%$, Table $1 ; 1.9 \pm 0.2 /$ $\mathrm{hr}, n=21)$. Thus, spike and wave activities appear to be independently regulated during development.

\section{Spikes exhibit rapid rates of rise}

Accurate assessment of spike kinetics required more detailed examination of their rapidly rising phase. Continuous imaging of dye-loaded cells with an SIT camera and frame capture at 33 $\mathrm{Hz}$ substantially improved the resolution achieved by imaging at $0.2 \mathrm{~Hz}$. Cells could be examined for periods up to $6 \mathrm{~min}$ without affecting survival and differentiation. Digital analysis of the rise of calcium spikes at $50 \mathrm{msec}$ intervals revealed a time to peak of $1.0 \pm 0.1 \mathrm{sec}$, with a monotonic rise both in the nucleus and in the cytoplasm $(n=7)$. The nuclear region showed 


\begin{tabular}{|c|c|c|c|}
\hline & $\begin{array}{l}\text { Spikes } \\
(\%)\end{array}$ & $\begin{array}{l}\text { Waves } \\
(\%)\end{array}$ & $\begin{array}{l}\text { None } \\
(\%)\end{array}$ \\
\hline \multicolumn{4}{|l|}{$\begin{array}{l}\text { Young neurons } \\
(6-8 \mathrm{hr} \text { in vitro })\end{array}$} \\
\hline $\begin{array}{l}\text { Control } 10 \mathrm{mM} \mathrm{Ca}^{2+} \\
n=80\end{array}$ & 35 & 34 & 31 \\
\hline $\begin{array}{l}\mathrm{Ni}^{2+}(50 \mu \mathrm{M}) \\
\quad n=43\end{array}$ & 19 & 49 & 32 \\
\hline $\begin{array}{l}\text { TTX }(1 \mu \mathrm{g} / \mathrm{ml}) \\
\quad n=42\end{array}$ & 7 & 57 & 36 \\
\hline $\begin{array}{l}\mathrm{Ni}^{2+}(2 \mathrm{mM}) \\
n=36\end{array}$ & 0 & 47 & 53 \\
\hline $\begin{array}{c}0\left[\mathrm{Ca}^{2+}\right]_{0} \\
n=32\end{array}$ & 0 & 3 & 97 \\
\hline $\begin{array}{l}\text { Control } 1 \mathrm{mM} \mathrm{Ca}^{2+} \\
\quad n=26\end{array}$ & 50 & 20 & 30 \\
\hline $\begin{array}{c}\mathrm{Ni}^{2+}(5 \mathrm{mM}) \\
n=54\end{array}$ & 0 & 4 & 96 \\
\hline \multicolumn{4}{|l|}{$\begin{array}{l}\text { Mature neurons } \\
\quad(17-22 \mathrm{hr} \text { in vitro })\end{array}$} \\
\hline $\begin{array}{l}\text { Control } 10 \mathrm{mM} \mathrm{Ca}^{2+} \\
n=85\end{array}$ & 19 & 38 & 43 \\
\hline $\begin{array}{l}\mathrm{Ni}^{2+}(50 \mu \mathrm{M}) \\
n=43\end{array}$ & 19 & 49 & 32 \\
\hline $\begin{array}{l}\operatorname{TTX}(1 \mu \mathrm{g} / \mathrm{ml}) \\
\quad n=51\end{array}$ & 4 & 41 & 55 \\
\hline
\end{tabular}

The incidence of spike and wave activity is indicated for the number of cells analyzed in each condition. In young neurons in the presence of $10 \mathrm{mM} \mathrm{Ca}^{2+}$, blockade of LVA calcium current with $50 \mu \mathrm{M} \mathrm{Ni}{ }^{2+}$ or $\mathrm{Na}^{+}$current with TTX reduces the incidence of spikes by an amount equal to the increase in incidence of waves in the cell body. Blockade of LVA and HVA calcium currents with 2 $\mathrm{mM} \mathrm{Ni}{ }^{2+}$ eliminates spikes but not waves. Replacement of calcium with magnesium abolishes both. In the presence of $1 \mathrm{mM} \mathrm{Ca}^{2+}$, spike frequency is higher, the wave frequency is correspondingly lower, while the percentage of cells active remains the same. Both spikes and waves are blocked by $5 \mathrm{~mm} \mathrm{Ni}^{2+}$. In mature neurons in the presence of $10 \mathrm{mM} \mathrm{Ca}{ }^{2+}$, blockade of LVA calcium current with $50 \mu \mathrm{M} \mathrm{Ni}^{2+}$ has no effect. Selective blockade of spikes only in young neurons by $50 \mu \mathrm{M} \mathrm{Ni}^{2+}$ is consistent with the role of LVA calcium current in spike generation and the reduced incidence of this current in mature neurons. Block of $\mathrm{Na}^{+}$current with TTX greatly reduces spike incidence; however, substantial variation of wave incidence is observed that may obscure the inverse relation between spike and wave incidence. Cells $(n)$ from $\geq 10$ cultures were imaged for $1 \mathrm{hr}$ under the conditions indicated and analyzed as described.

a greater increase in fluorescence (Fig. 2), as seen also in spikes acquired more slowly by imaging at $5 \mathrm{sec}$ intervals. This increase was not due to the larger volume of the nucleus, since there was no difference in the baseline fluorescence intensity of the nucleus from the surrounding region. The decay of spikes analyzed by continuous imaging was fit with a double exponential, with a fast time constant of $7.5 \pm 1.0 \mathrm{sec}(n=7)$ that is not significantly different from the value from confocal imaging $(P>0.05$; Fig. $2 B$ ). The limited duration of imaging precluded analysis of the slow time constant in most cases.

The frequency of spikes/neuron $\times$ hr observed with continuous imaging should be in agreement with that observed by intermittent imaging. Since the latter method revealed spikes in $35 \%$ of neurons with an average frequency of two or three events per hour, continuous imaging of 10 neurons for $6 \mathrm{~min}$ each (equivalent to a $1 \mathrm{hr}$ period for a single neuron) should capture one spike. Among 80 neurons imaged for $6 \mathrm{~min}$ each, seven spontaneous spikes were detected (Fig. 2A), consistent with this expectation. Further, the decay time constants and relative subcellular intensities of fluorescence were similar when measured by either method.

\section{Spontaneous spikes and waves in vivo}

All neuronal properties previously studied in these cultures have been demonstrated to have similar developmental patterns of expression in vivo (see Holliday and Spitzer, 1991, for review). Such comparison is critical for assessment of the physiological significance of spikes and waves. Both were generated in cells imaged on the ventral aspect of the spinal cord, and spikes were more prominent than in culture (Fig. 3). Cells generating spikes in vivo were likely to be neurons, since spikes are neuron specific in vitro. These cells were largely bilateral, and occupied the positions of motoneurons that are a major fraction of the cells studied in culture (Bixby and Spitzer, 1984b; Henderson et al., 1984). At early neural tube stages (corresponding to $2-6 \mathrm{hr}$ in vitro), $50 \%$ of cells on the ventral surface of the spinal cord exhibited spikes at an average frequency of 10 per hour $(n=3$ spinal cords). The incidence and average frequency of spiking declined to $20 \%$ and two per hour at tailbud stages (corresponding to $9-15 \mathrm{hr}$ in vitro; $n=5$ spinal cords). In culture, elevations of $\left[\mathrm{Ca}^{2+}\right]_{i}$ are cell autonomous and not an emergent property of interactions among ensembles of neurons, since most neurons, including active cells, were not contiguous with others. The greater frequency of calcium spikes in vivo implies either that the threshold for eliciting them is lower than in culture, perhaps due to stimulation by cell-cell contacts or secreted factors, or that cells are coupled and therefore generate higher apparent levels of activity. Quantitative assessment of wave incidence and frequency was precluded by the increased noise level generated by movement of cells in the spinal cord.

The appearance of synchronously active cells characterized the spinal cord at somewhat later stages when neurons are known to be electrically coupled (Spitzer, 1982). Groups of two to four cells in a field of $\sim 100$ generated seemingly synchronous spikes repeatedly, two to five times (Fig. $4 A$ ). The probability of coactivity of three cells occurring five times at random is $<2 \times 10^{-5}$. Remarkably, these cells were not always contiguous, an observation in agreement with neurite extension that has been shown to begin at these stages (Hayes and Roberts, 1973; Taylor and Roberts, 1983). Apparently synchronous calcium spikes were also observed between closely apposed neurons in culture (Fig. $4 B$ ). The random probability that these two ncurons would be coactive twice is $<10^{-4}$. Coactivity of closely apposed neurons is unlikely to be due to stimulation by the same trigger signal in culture, since active neurons in apparent contact with one another were coactive in only a few cases. Although electrical coupling has not been examined between neurons in vitro, the presence of coactivity indicates that it may also occur between cultured neurons at $6-8 \mathrm{hr}$ after plating.

Figure 3. Spontaneous transient elevations of $\left[\mathrm{Ca}^{2+}\right]_{i}$ in the intact embryonic spinal cord (stage 19), imaged at $0.2 \mathrm{~Hz}$. for $1 \mathrm{hr}$. Top, Single image displays 84 cells visualized on the ventral aspect of the cord, 41 of which exhibited spikes during a 10 min period. Middle, Aggregate spontaneous activity; cells are represented by circles, and the number in each indicates the spikes produced in that cell (1-13). Bottom, Time course of a calcium spike in the active cell indicated by the arrow, digitized at $0.2 \mathrm{~Hz}$; rapid rate of rise and double exponential decay of fluorescence identify it as a neuron. 
A

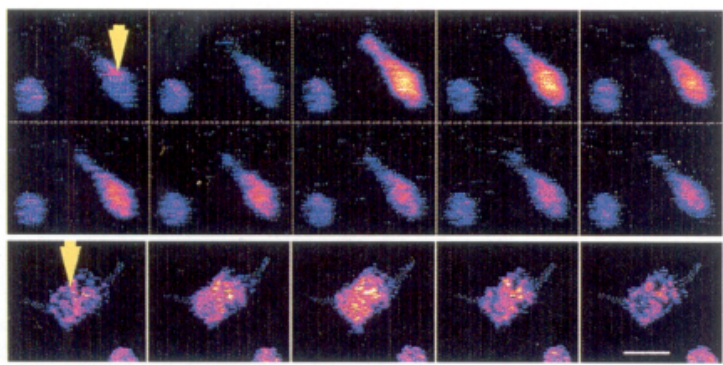

B

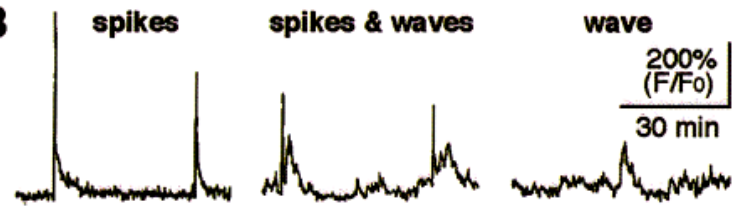

Figure 1. Spontaneous transient elevations of $\left[\mathrm{Ca}^{2+}\right]_{i}$ at $6-8 \mathrm{hr}$ in vitro. $A$. Fast spike (top) and slow wave (bottom) in two spinal neurons (arrows). The non-neuronal cells are inactive. Images were acquired at 0.2 $\mathrm{Hz}$ and displayed at $5 \mathrm{sec}$ and $2.5 \mathrm{~min}$ intervals (top and bottom; left to right). Fluo- 3 fluorescence is indicated in pseudocolor; gold indicates $400-600 \%$ of baseline. Scale bar, $25 \mu \mathrm{m}$. B, Elevation of $\left[\mathrm{Ca}^{2+}\right]_{i}$ in spikes, spikes followed by waves, and waves (left to right) in three neurons, digitized at $0.2 \mathrm{~Hz}$. Spikes and waves may originate by a common mechanism. Fast and slow time constants for the two spikes at left are $9.1 \mathrm{sec}, 3.5 \mathrm{~min}$ and $20 \mathrm{sec}, 2.0 \mathrm{~min}$, respectively.

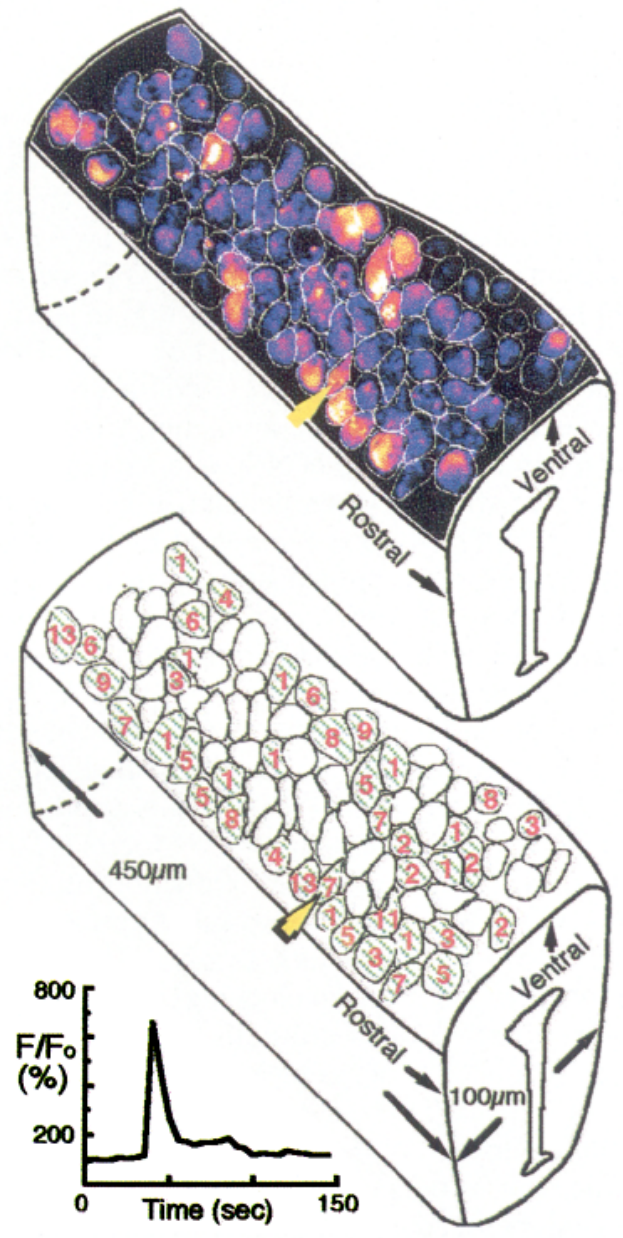

A
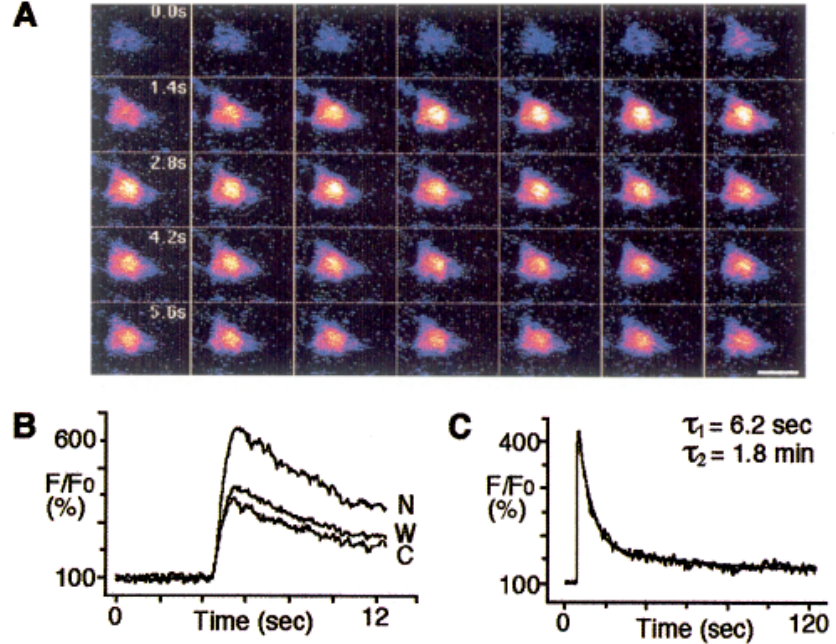

Figure 2. Kinetics of calcium spikes; neuron at $7 \mathrm{hr}$ in vitro. A, Images were acquired continuously at $33 \mathrm{~Hz}$ and displayed at $0.2 \mathrm{sec}$ intervals. Scale bar, $25 \mu \mathrm{m}$. B. Time course of increase and decrease in $\left[\mathrm{Ca}^{2+}\right]_{i}$ in the same neuron, digitized at $20 \mathrm{~Hz} . N$, nucleus; $C$, cytoplasm; $W$, whole cell. $C$, Double exponential time course of decrease in the same cell, digitized at $2 \mathrm{~Hz} . \tau_{1}$ and $\tau_{2}$ indicate fast and slow time constants.
A
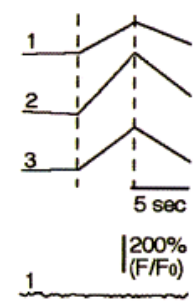

2

3
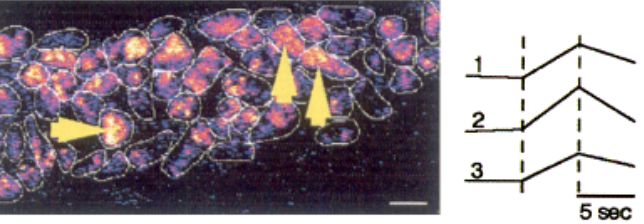

B

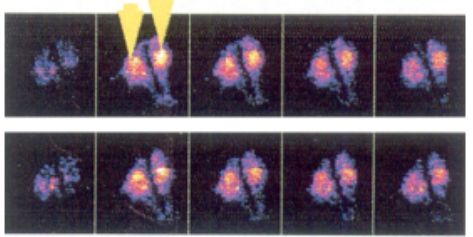

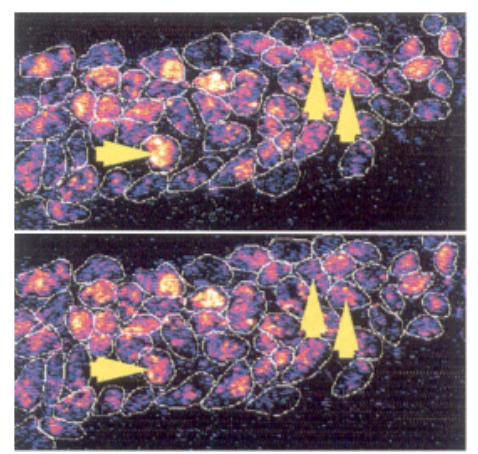

Figure 4. Coactivity of spiking cells. Images were acquired and intensities digitized at $0.2 \mathrm{~Hz}$. A, Cells in the spinal cord (stage 24) have been outlined to clarify their boundaries. Top, Coordinated spontaneous calcium spikes occur in three cells (arrows; 1, 2, 3 are left to right). Middle, Return to baseline. Bottom, Spikes occur again in the same cells $19 \mathrm{~min}$ later. These events recurred five times during $1 \mathrm{hr}$, at 2,21,35,40, and $50 \mathrm{~min}$. $B$, Adjacent neurons in culture are coactive twice during a 1 hr period, producing spikes at 12 and $28 \mathrm{~min}$ (arrows; 1, 2 are left, right). Images acquired and displayed at $5 \mathrm{sec}$ intervals. Eight hours in vitro. Scale bar, $25 \mu \mathrm{m}$. 
Figure 5. Generation of spikes by calcium-dependent action potentials. $A$ : Left, Spontaneous calcium spike is mimicked by a spike in the same neuron elicited in response to $0.1 \mathrm{msec}$ extracellular electrical stimulation. Images acquired and digitized at $0.2 \mathrm{~Hz}$. Right, Line scans of another neuron show that stimuli of increasing strength elicit an elevation of calcium that rises rapidly in an all-or-none manner. The long duration of the calcium spike is likely to reflect release from intracellular stores (Fig. 6; see also Holliday et al., 1991). Seven hours in vitro. B. Spikes are propagated rapidly. $L e f t$, Repeated spontaneous spikes in the soma and growth cone are synchronous; images acquired and digitized at $0.2 \mathrm{~Hz}$. Bars under traces indicate regions expanded to the right. Right, Line scans of another neuron demonstrate that similar spikes can be elicited in both the soma and growth cone following stimuli (arrows) to either region. Spikes arise within the same 4 msec interval, noted by arrowhead and expanded on $20 \mathrm{msec}$ time base. Seven hours in vitro. $C$, Elimination of LVA calcium current or sodium current raises action potential threshold in a young neuron from -36 $\mathrm{mV}$ to -21 or $-7 \mathrm{mV}$, respectively, in a computer model. Selective blockade of LVA calcium current or sodium current reduces the incidence of spikes as predicted (see text and Table 1).
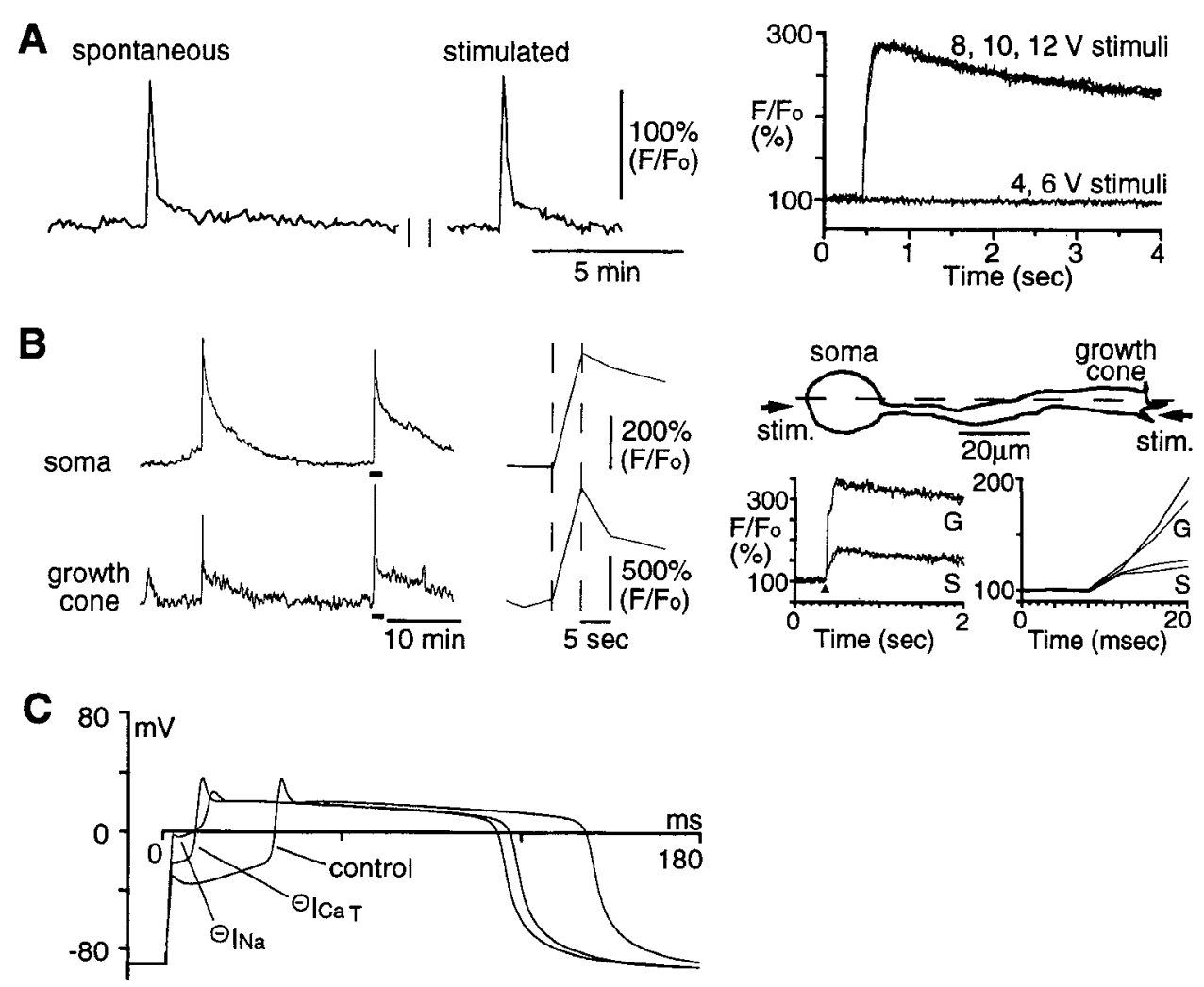

\section{Underlying mechanisms of spikes and waves}

Since generation of spikes and waves requires extracellular calcium, we determined whether these signals are generated by calcium influx during action potentials in cultured neurons. Spontaneous spikes can be mimicked by elevations of fluorescence generated by brief electrical stimulation of the same cells with extracellular electrodes to trigger action potentials (Fig. $5 \mathrm{~A}$, left; $n=5$ ). Analysis of the rate of rise of elicited spikes by confocal line scan with $4 \mathrm{msec}$ time resolution showed that they reached their peak in $0.7 \pm 0.01 \sec (n=12)$ and were generated in an all-or-none manner (Fig. 5A, right; $n=5$ ). Focal stimulation elicited spikes in either soma or growth cone; their amplitudes were similar irrespective of the site of stimulation. Line scan analysis showed that these spikes were propagated rapidly throughout the length of the cell within $4 \mathrm{msec}$ in either direction (Fig. 5B, right; $n=3$ ). The results show that these spikes have characteristics of action potentials and suggest that action potentials are required for their generation. Spontaneous calcium spikes also possess characteristics of action potentials. They travel rapidly throughout the cell, with no detectable delay between soma and growth cone at $5 \mathrm{sec}$ time resolution (Fig. $5 B$, left; $\sim 50 \mu \mathrm{m}$ ) as well as at $50 \mathrm{msec}$ resolution (data not shown). Such rapid conduction could promote synchronized spike activity of noncontiguous cells in the spinal cord that are connected by neurites (Fig. $4 A ; n=3$ ). In addition, calcium channel blockers such as $2 \mathrm{mM} \mathrm{Ni}{ }^{2+}, 10 \mathrm{mM} \mathrm{Co}^{2+}$, or $10 \mu \mathrm{M} \omega$-conotoxin, which block both HVA calcium currents and calcium-dependent action potentials, eliminated spikes in young neurons $(n \geq 19)$.
Further evidence indicates that action potentials generate spikes and defines characteristics of underlying trigger events as well. Elimination of low-voltage-activated (LVA) calcium current or sodium current raised the threshold for action potential initiation in young neurons from $-36 \mathrm{mV}$ to -21 or $-7 \mathrm{mV}$ in computer simulations (Fig. 5C; O'Dowd et al., 1988; Lockery and Spitzer, 1992; Gu and Spitzer, 1993b). This result yielded several experimentally testable predictions, provided depolarization is the immediate trigger of spontaneous action potentials and antecedent trigger events depolarize cells to a variety of levels that are sufficient to activate voltage-dependent currents. First, if spikes are produced by action potentials, then selective blockade of LVA calcium current or sodium current should reduce their incidence. Second, blockade of sodium current should create a greater reduction since it elevates the threshold of the action potential to a higher level. Experimentally, blockade of LVA calcium or $\mathrm{Na}^{+}$currents by application of $50 \mu \mathrm{M}$ $\mathrm{Ni}^{2+}$ or $1 \mu \mathrm{g} / \mathrm{ml}$ tetrodotoxin (TTX) reduced spike incidence by $50 \%$ and $80 \%$, respectively (Table 1 ). Moreover, lowering the threshold of action potentials by reduction of surface charge should promote the incidence of spikes. As predicted, reduction of $\left[\mathrm{Ca}^{2+}\right]_{\mathrm{o}}$ from 10 to $1 \mathrm{~mm}$ increases spike incidence, by $43 \%$. These data show that effects of blocking LVA calcium or sodium currents in young neurons are both qualitatively and quantitatively as predicted if spontaneous action potentials produce spikes. At the same time, the results also support the view that the immediate trigger for action potentials is an electrical event that can depolarize cclls to a range of potentials. Simultaneous recording of spontaneous spikes and action potentials did not 
appear to be feasible with conventional techniques since intracellular or extracellular electrical recording often provoked elevation of $\left[\mathrm{Ca}^{2+}\right]_{i}$.

In contrast to its effect on young cells, blockade of T current in mature neurons did not affect spike incidence (Table 1). However, spikes in mature neurons were eliminated by tetrodotoxin, indicating that calcium influx during spikes is mediated by sodium-dependent action potentials. These results are consistent with the roles of these currents on action potential threshold and calcium influx in computer simulations (Lockery and Spitzer, 1992; Gu and Spitzer, 1993b); thus, the action potential is likely to underlie spikes in mature neurons as well.

We performed experiments with fura-2AM to provide a quantitative estimate of the levels of intracellular calcium achieved during spikes (Fig. 6). In young neurons, the resting level of intracellular calcium in the cell body was $52 \pm 4 \mathrm{nM}(n=24)$. Intracellular calcium rose to $530 \pm 49 \mathrm{nM}(n=9)$ when spikes were elicited by focal electrical stimulation. The rise time and rapid time constant of decay of $\left[\mathrm{Ca}^{2+}\right]_{i}$ were $1 \pm 0.1 \mathrm{sec}$ and 12 $\pm 1 \mathrm{sec}$, which are comparable to those obtained from fluo-3 imaging. Previous studies showed that $20 \mathrm{~mm}$ caffeine can elicit calcium release from stores in mature neurons, while young neurons were not affected (Holliday et al., 1991). Higher concentrations of caffeine are effective on young neurons, and produce a transient elevation of $\left[\mathrm{Ca}^{2+}\right]_{i}$ similar to that in mature neurons. Caffeine can produce similar transient elevations of $\left[\mathrm{Ca}^{2+}\right]_{i}$ with or without extracellular calcium, suggesting that it directly stimulates release from intracellular calcium stores. Incubation with $\sim 50 \mathrm{~mm}$ caffeine to suppress release caused a significant reduction in the elevation of $\left[\mathrm{Ca}^{2+}\right]_{i}$ ensuing from electrical stimulation, to $191 \pm 28 \mathrm{nM}(n=5 ; t$ test, $p<0.001)$. This result indicates that intracellular stores contribute to the elevation of calcium during spikes. Elevation of $\left[\mathrm{Ca}^{2+}\right]_{i}$ is also apparent in the growth cone following stimulation. The resting level was $32 \pm 4 \mathrm{~nm}(n=15)$ and rose to $203 \pm 22 \mathrm{~nm}(n=$ 9). Both values are significantly lower than those in the soma ( $t$ test, $p<0.0001$ for both).

The mechanism by which waves are generated in the cell body is different from that of spikes. Waves were not suppressed by channel blockers at concentrations that suppress voltage-dependent calcium and sodium currents (Table 1), demonstrating that action potentials are not involved in generating waves. Waves persisted when external calcium was reduced to $1 \mathrm{~mm}$, allowing testing of a ratio of nickel to calcium that was toxic in $10 \mathrm{~mm}$ calcium. Waves recorded in $1 \mathrm{~mm}$ external calcium were blocked by $5 \mathrm{~mm} \mathrm{Ni}^{2+}$ (Fig. $7 A ; n=54$ ). We also imaged 11 cultured neurons in medium containing $2 \mathrm{mM} \mathrm{Ca}^{2+} / 10 \mathrm{mM} \mathrm{Ni}^{2+}$ (the same ratio of $\mathrm{Ca}^{2+}$ to $\mathrm{Ni}^{2+}$ ) for 20-30 min, during which wave activity in all of these neurons was blocked. Nine of these neurons were initially imaged without $\mathrm{Ni}^{2+}$ for $20 \mathrm{~min}$, then with $\mathrm{Ni}^{2+}$ for 20-30 min, and finally, after washout of $\mathrm{Ni}^{2+}$, for a further $20 \mathrm{~min}$. Spikes or waves were seen in $67 \%$ of neurons during the initial period of imaging and were observed with the same incidence following recovery, indicating that the $\mathrm{Ni}^{2+}$ blockade is reversible.

However, the mechanism generating waves appears not to be voltage dependent, since depolarization with $50 \mathrm{mM} \mathrm{KCl}$ in the presence of concentrations of blockers that suppress LVA and HVA currents did not elicit elevation of intracellular calcium (Fig. $7 B ; n=9$ ). The mechanism generating waves also appears not to involve activation by excitatory neurotransmitters to which the neurons become sensitive (Bixby and Spitzer, 1984b).
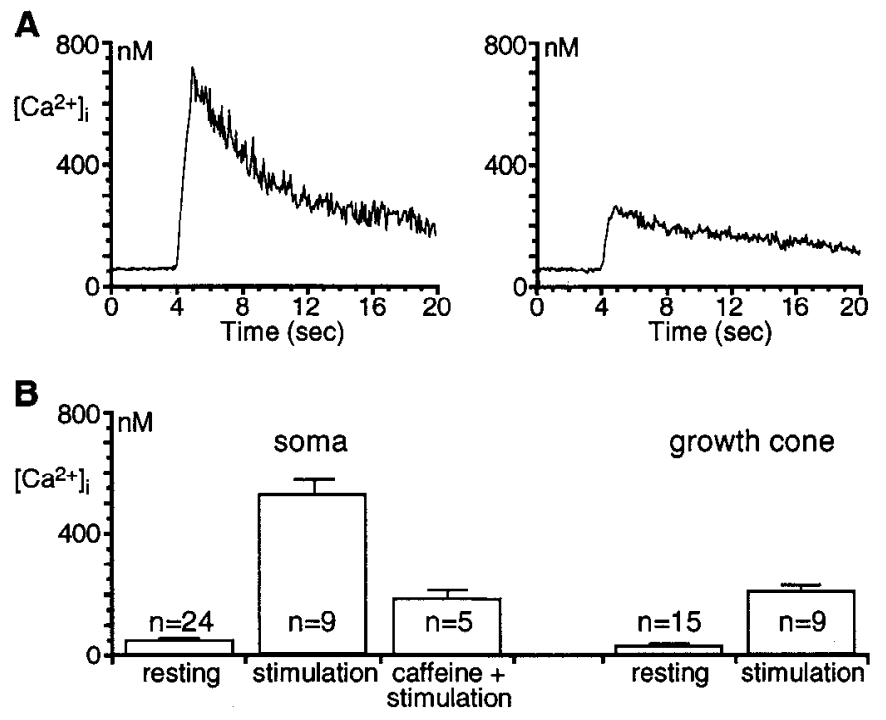

Figure 6. Intraccllular calcium levels achieved during elicited spikes, estimated from fura-2 fluorescence. $A$ : Left, Spike elicited by electrical stimulation shows an elevation of calcium in the soma from 50 to 700 nM. Right, Depletion of stores with caffeine reduces the elevation of calcium following stimulation of a spike to $250 \mathrm{nM}$ in the same neuron. Data acquired and displayed at $12.5 \mathrm{~Hz}$. Seven hours in vitro. B, Mean baseline and peak values of $\left[\mathrm{Ca}^{2+}\right]_{i}$ in the soma \pm caffeine and in the growth cone. Six to eight hours in vitro. Growth cones were not sufficiently stable to allow assessment of stores with caffeine.

Glutamate caused elevation of intracellular calcium in $90 \%$ of neurons at $6-8 \mathrm{hr}(n=25)$ that was reversibly blocked by a combination of 6,7-dinitroquinoxaline-2,3-dione (DNQX) and kynurenic acid $(100 \mu \mathrm{M}$ and $500 \mu \mathrm{M}, n=10)$. Neither wave nor spike incidence and frequency were affected by the combination of these blockers during $1 \mathrm{hr}$ periods of imaging (Fig. $7 A ; n=$ 8).

Waves originating in the soma did not invade growth cones in most neurons, and only large ones were detected in neurites. Unlike rapid propagation of spikes, these waves usually required $30-70 \mathrm{sec}$ to reach growth cones $(\sim 50 \mu \mathrm{m})$. This propagation rate is in agreement with the velocity of diffusion of calcium but not inositol trisphosphate in Xenopus oocyte cytoplasm (Fig. $8 A$; Albritton et al., 1992). Waves also arose in growth cones and were not generally propagated to the cell body. They have the same pharmacological sensitivities as waves generated in the soma (Tables 1,2 ). The failure of waves to propagate from growth cones to cell body may be due to size mismatch of cytoplasmic volumes between neurites and soma.

Although spikes and waves are generated by different mechanisms, they appear closely associated. Spikes were followed immediately by waves in some cells (Fig. $1 B$ ). Blockade of spikes enhanced the incidence of waves by an amount equal to the decrease in spike incidence in young neurons (Table 1). The distribution of wave amplitudes was unchanged (Fig. $8 B$ ), indicating that newly added waves are not different from those initially expressed. Furthermorc, reduction in external calcium raised the incidence of spikes, consistent with the reduction in threshold of voltage-dependent calcium currents (Gu and Spitzer, 1993b), and decreased the incidence of waves. These results suggest a direct linkage between them (Dupont et al., 1991).

\section{Functions of spikes and waves in neuronal development}

Normal differentiation of Xenopus spinal neurons in cullure requires the presence of extracellular calcium during a sensitive 

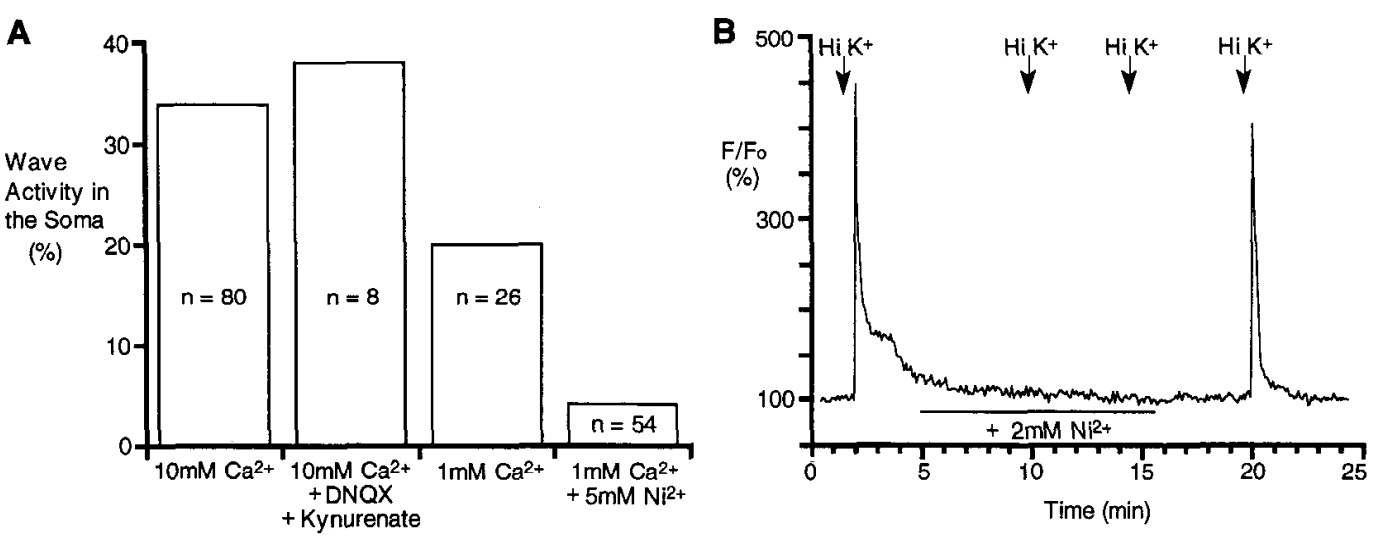

Figure 7. Mechanisms of generation of waves. $A$, Waves can be blocked by high concentrations of $\mathrm{Ni}^{2+}$, but are unaffected by glutamate receptor blockers. Incidence of waves during a $1 \mathrm{hr}$ period. Neurons exhibit waves in either 10 or $1 \mathrm{~mm}$ calcium. Waves are unaffected by $150 \mu \mathrm{M}$ DNQX and $500 \mu \mathrm{M}$ kynurenic acid that block calcium elevations in response to glutamate, but are suppressed by $5 \mathrm{~mm} \mathrm{Ni}{ }^{2+}$. Neurons at 6-9 hr in vitro. $B$, Waves are not produced by membrane depolarization. Spikes elicited by stimulation with $50 \mathrm{~mm} \mathrm{KCl}$ in the presence of 2 mM calcium are blocked by $2 \mathrm{~mm} \mathrm{Ni}{ }^{2+}$, which blocks voltage-gated calcium channels but not waves $(n=9)$. Data digitized at $0.2 \mathrm{~Hz}$. Neurons at $7-8 \mathrm{hr}$ in vitro.

period (Holliday and Spitzer, 1991). Do spikes and waves influence the appearance of calcium-dependent properties? Spikes are more likely to exert their effects in the soma than waves, since ratios of nuclear to cytosolic fluorescence increased during spikes but not during waves (Fig. $1 A$ ), although there was no distinctive difference in loading of the nucleus and cytoplasm with the indicator. These results imply that spikes may have a more pronounced effect on $\left[\mathrm{Ca}^{2+}\right]_{i}$ in the nuclear region (Hernandez-Cruz et al., 1990; Holliday et al., 1991; see also Connor,

\begin{tabular}{|c|c|c|}
\hline & $\begin{array}{l}\text { Waves } \\
(\%)\end{array}$ & $\begin{array}{l}\text { Frequency } \\
(\text { mean } \pm \text { SEM) }\end{array}$ \\
\hline \multicolumn{3}{|l|}{$\begin{array}{l}\text { Young neurons } \\
(6-8 \mathrm{hr} \text { in vitro })\end{array}$} \\
\hline $\begin{array}{l}\text { Control } 10 \mathrm{mM} \mathrm{Ca}^{2+} \\
n=15\end{array}$ & 100 & $8.8 \pm 1.0$ \\
\hline $\begin{array}{l}\text { TTX }(1 \mu \mathrm{g} / \mathrm{ml}) \\
n=8\end{array}$ & 100 & $8.3 \pm 1.1$ \\
\hline $\begin{array}{l}\mathrm{Ni}^{2+}(2 \mathrm{mM}) \\
\quad n=8\end{array}$ & 88 & $8.6 \pm 1.6$ \\
\hline $\begin{array}{l}\text { Control } 1 \mathrm{mM} \mathrm{Ca}^{2+} \\
n=4\end{array}$ & 100 & $9.5 \pm 0.9$ \\
\hline $\begin{array}{l}\mathrm{Ni}^{2+}(5 \mathrm{mM}) \\
\quad n=5\end{array}$ & 0 & - \\
\hline \multicolumn{3}{|l|}{$\begin{array}{l}\text { Mature neurons } \\
(17-22 \mathrm{hr} \text { in vitro })\end{array}$} \\
\hline $\begin{array}{l}\text { Control } 10 \mathrm{mM} \mathrm{Ca}^{2+} \\
\quad n=11\end{array}$ & 100 & $9.3 \pm 0.9$ \\
\hline
\end{tabular}

The incidence and frequency are indicated for the number of cells analyzed in each condition. In young neurons, the incidence and frequency of waves are the same in 1 and $10 \mathrm{mM} \mathrm{Ca}{ }^{2+}$, and blockade of $\mathrm{Na}^{+}$current with TTX or calcium currents with $2 \mathrm{mM} \mathrm{Ni}^{2+}$ in the presence of $10 \mathrm{mM} \mathrm{Ca}^{2+}$ has no substantial effect. In the presence of $1 \mathrm{mM} \mathrm{Ca}^{2+}$, waves are blocked by $5 \mathrm{~mm} \mathrm{Ni}{ }^{2+}$. In mature neurons, wave incidence and frequency remain the same in $10 \mathrm{~mm} \mathrm{Ca}{ }^{2+}$. Cells $(n)$ from three or more cultures were imaged for $1 \mathrm{hr}$ under the conditions indicated and analyzed as described.
1993), although the interpretation of such increases in nuclear fluorescence can be problematic.

Evoked action potentials and ensuing calcium elevations in the growth cone have been shown to influence neurite extension in other systems (Cohan and Kater, 1986; Fields et al., 1990). Surprisingly, spontaneous spikes that are associated with calcium-dependent action potentials and cause calcium elevation in growth cones have no effect on extension of neurites of Xenopus spinal neurons (Figs. $5 B, 9$ ). Selective suppression of spikes by TTX or $2 \mathrm{~mm} \mathrm{Ni}^{2+}$ did not alter neurite length.

However, neurite extension in Xenopus spinal neurons is subject to changes in intracellular calcium (Holliday et al., 1991), raising the issue of the mechanism normally involved. Spontaneous waves generate fluctuations of intracellular calcium at a higher incidence and frequency in growth cones than in the soma $(100 \%, 8.8 \pm 1.0 / \mathrm{hr}, n=15$; Table 2$)$. Moreover, local waves occurred independently in separate growth cones of the same neuron (Fig. 8C). Waves are thus positioned to exert effects in the growth cone and may regulate extension of neurites. Neurites are typically short in the presence of calcium. When influx during waves was prevented by removal of extracellular calcium, neurons extended long processes (Fig. 9). Independent frequencies of waves in growth cones could account for variations in neurite lengths of multipolar neurons. Moreover, the developmental persistence of waves is compatible with the sensitivity of neurite extension to extracellular calcium throughout an extended period (Holliday and Spitzer, 1990).

\section{Discussion}

Embryonic spinal neurons exhibit two kinetically distinct spontaneous fluctuations in $\left[\mathrm{Ca}^{2+}\right]_{i}$ during a calcium-sensitive period of development. Oscillations of intracellular calcium have been reported in other differentiating neurons (Sorimachi et al., 1990a; Yuste et al., 1992; O’Donovan et al., 1993), in mature neurons (Tank et al., 1988; Sugimori and Llinas, 1990), as well as in non-neuronal cells (Berridge et al., 1988; Rink and Jacob, 1989; Cornell-Bell et al., 1990). Our results show that calcium spikes and calcium waves in individual Xenopus spinal neurons are mechanistically separable and may be required for expression of distinct aspects of differentiation. 

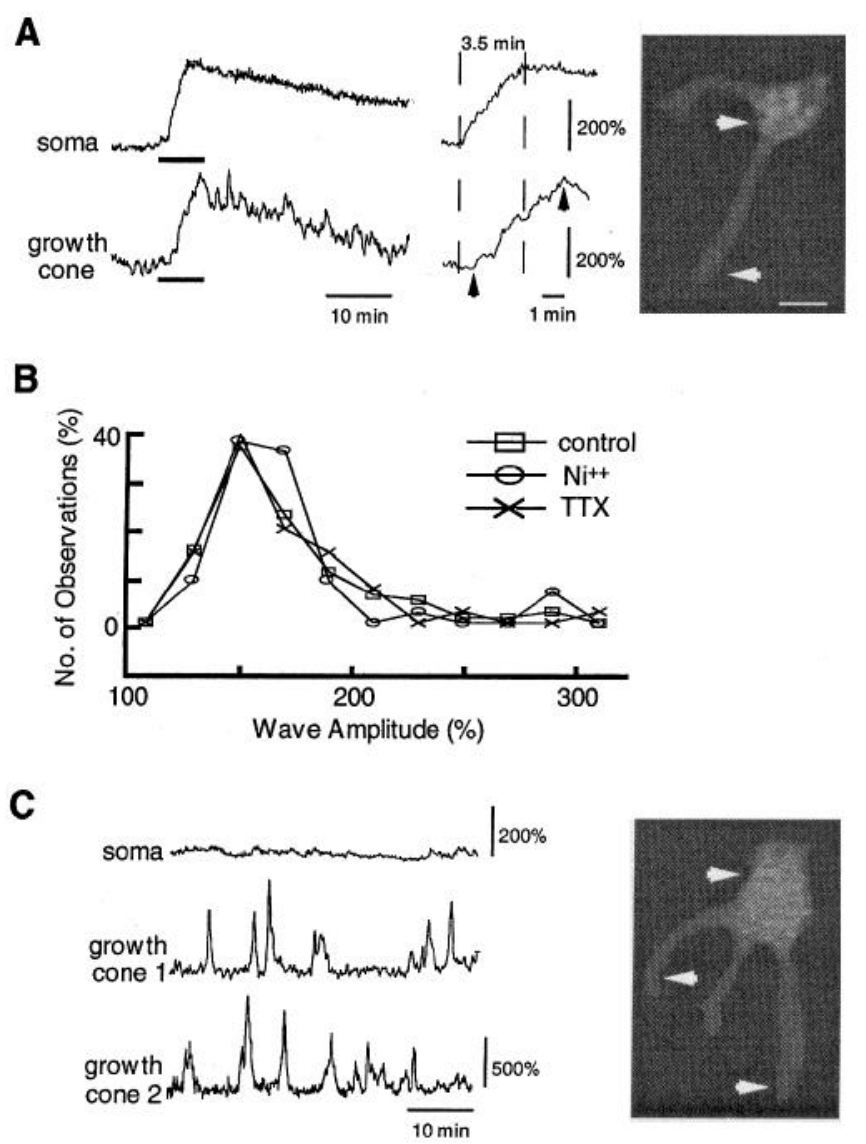

Figure 8. Propagation of waves in young neurons. Arrows indicate regions from which image intensities were digitized $(0.2 \mathrm{~Hz}) . A$, A large wave in the soma leads that in the growth cone. Bars under traces indicate regions expanded at right; arrow shows the arrival of the wave in the growth cone. The delay of $1 \mathrm{~min}$ is predicted for diffusion of calcium along a neurite $50 \mu \mathrm{m}$ in length (Albritton et al., 1992). A corresponding delay was seen in the other growth cone (not shown). $B$, Distribution of wave amplitudes of young cultured neurons is not affected by $\mathrm{Ni}^{2+}$ or TTX [mean values \pm SEM are $174 \pm 4$ (control), 174 $\pm 3\left(50 \mu \mathrm{M} \mathrm{Ni}^{2+}\right), 176 \pm 2(1 \mu \mathrm{g} / \mathrm{ml}$ TTX $) ; n \geq 29$ for each], although spike incidence is reduced (Table 1). $C$, Waves arise in growth cones at a higher frequency than in the soma, and neither waves nor spikes are recorded from the soma during asynchronous waves in two growth cones of the same cell (arrows; 1, 2 are left, right). The third growth cone exhibited similar behavior. Recording saline contained $1 \mu \mathrm{g} / \mathrm{ml}$ TTX. Scale bar, $25 \mu \mathrm{m}$.

Several lines of evidence indicate that spikes are generated by spontaneous action potentials. In addition, the neuronal specificity of spikes is consistent with the observation that action potentials promote calcium influx in these neurons. The results suggest that LVA calcium current triggers action potentials though the activation of sodium current. In addition, they confirm the demonstration that LVA calcium current is functionally involved in regulating intracellular calcium in young neurons, and support the hypothesis that it has lost this function in mature neurons (Gu and Spitzer, 1993b). These data are consistent with observations that sodium-dependent action potentials can trigger voltage-dependent calcium entry in other systems (Chen et al., 1990; Sorimachi et al., 1990a,b; Agoston et al., 1991; Jaffe et al., 1992; Lev-Ram et al., 1992). Thus, there is a mechanistic basis for the well-known observation that sodium-dependent electrical activity influences neuronal development (Shatz, 1990).

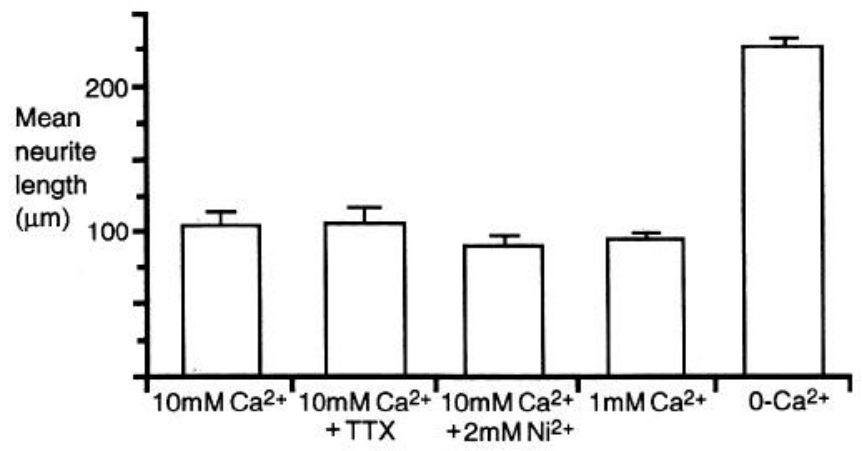

Figure 9. Regulation of neurite length by calcium waves. Suppression of spikes with $1 \mu \mathrm{g} / \mathrm{ml}$ TTX or $2 \mathrm{mM} \mathrm{Ni}^{2+}$ has no effect relative to control $(P>0.16, t$ test), while elimination of waves by removal of extracellular calcium promotes neurite extension $(P<0.001)$. Values are means for the longest neurite of over 50 mature neurons from three or more cultures.

Spontaneous spikes are initiated in the soma of neurons that have not yet extended neurites. Whether spontaneous spikes originate in soma or growth cone once neurite outgrowth has occurred remains to be determined. Reduction of spike amplitude with caffeine indicates that stores are also involved in the production of spikes. This observation implies that calcium influx during calcium-dependent action potentials is sufficient to trigger release from stores. The concentration of caffeine used to stimulate young neurons $(40-60 \mathrm{~mm})$ could have other effects in addition to the stimulation of calcium stores. Since caffeine produces only a transient elevation of $\left[\mathrm{Ca}^{2+}\right]_{i}$ in the presence or absence of extracellular calcium, it is unlikely to induce significant calcium influx a few minutes later when neurons are electrically stimulated. In addition, lower concentrations of caffeine applied to mature neurons elicit the same effect as application of these higher concentrations to young neurons (Holliday et al., 1991), suggesting that any side effects on young neurons may be minor. In contrast, spontaneous elevations of $\left[\mathrm{Ca}^{2+}\right]_{i}$ in neonatal rat cortex are unaffected by suppression of sodium current with TTX (Yuste and Katz, 1992), indicating that other mechanisms are also involved in implementing programs of development invoked by activity (Constantine-Paton et al., 1990; Komuro and Rakic, 1993).

Calcium influx during the calcium-sensitive period could stimulate transcription (M. Sheng et al., 1990; Dash et al., 1991; Bading et al., 1993; Lerea and McNamara, 1993; H. Z. Sheng et al., 1993). Changes in calcium levels in the nucleus during spikes may regulate calcium-dependent gene expression. Previous work has shown that application of $\mathrm{Ni}^{2+}$ at a ratio of 10 mM Ca ${ }^{2+} / 2 \mathrm{~mm} \mathrm{Ni}^{2+}$ blocks appearance of GABA as well as the increase in rate of activation of delayed rectifier potassium current (Desarmenien and Spitzer, 1991; Spitzer et al., 1993). Since this ratio blocks voltage-activated $\mathrm{Ca}^{2+}$ current and suppresses spikes but spares waves, spikes may be specifically required for these aspects of neuronal differentiation. This possibility is supported by. observations that inhibitors of RNA synthesis achieve a suppression of differentiation of these neurons similar to that obtained by blocking calcium influx (Ribera and Spitzer, 1989; Desarmenien and Spitzer, 1991; Spitzer et al., 1993). These findings identify a significance of calciumdependent action potentials in early neuronal development.

The double exponential decay of most spikes may be due to two different buffer mechanisms. Neurons possess several buffer 
systems to stabilize $\left[\mathrm{Ca}^{2+}\right]_{i}$ (Miller, 1991). Spikes require calcium release from intracellular stores in addition to influx through calcium channels, in agreement with previous studies (Barish, 1991; Holliday et al., 1991). A large and rapid increase of $\left[\mathrm{Ca}^{2+}\right]_{i}$ may trigger both fast and slow buffering systems that result in double exponential decay. This view is consistent with the observation of a single fast decay component of small spikes, accounted for by the fast buffering system. This model assumes no major continuing influx or release from intracellular stores during spike decay.

Waves appear to require calcium influx, since they are dependent on external calcium and can be blocked by $\mathrm{Ni}^{2+}$ at a ratio of $1 \mathrm{mM} \mathrm{Ca}^{2+} / 5 \mathrm{mM} \mathrm{Ni}^{2+}$. Spontaneous action potentials, conventional voltage-gated calcium channels, and glutamate receptors are not involved in generating this activity. These results implicate a different calcium pathway for waves. Candidates include mechanosensitive channels (Lane et al., 1991), products of intracellular metabolism, and influx stimulated by depletion of intracellular calcium stores that activates a calcium current (Rerridge and Irvine, 1989; Putney, 1990; Hoth and Penner, 1992; Randriamampita and Tsien, 1993). Depletion-activated channels are blocked by $\mathrm{Ni}^{2+}$ at concentrations that block waves (Zweifach and Lewis, 1993).

Waves appear to have different functions in the soma and in the growth cone. In the soma, both the observation of spikes followed immediately by waves and the inverse relation of waves and spikes indicate a connection between these two activities in young neurons. A similar relationship may exist in mature neurons, requiring a larger sample size for detection in the face of increased variability apparent at these stages. This linkage may entail depolarization by calcium influx associated with waves. Slow or weak depolarization could produce waves. Rapid and strong depolarization sufficient to activate LVA calcium or sodium currents would lead to generation of spikes that are then followed by waves, since spikes are generated more rapidly. This scheme implies a common origin for both events. Such an electrical event associated with triggering of waves must be small or fast, since it is not detected when spikes are examined by continuous imaging. Moreover, spikes can be developmentally regulated independent of the triggering events since spikes require activation of additional currents. The fact that waves are detected following spikes in only a few cases may be the result of recruitment of buffer systems that can overcome slowly rising waves. Spikes are not triggered by high frequencies of locally generated large-amplitude waves in the growth cone. This may be the result of greater dependence of these signals on calcium stores, or reduction in the density of relevant voltage-dependent channels that generate spikes.

In the growth cone, waves may regulate neurite extension since their elimination by removal of external calcium promotes neurite outgrowth. In principle, this observation could be due to an extracellular effect of the absence of calcium. However, the reduction of elevations of $\left[\mathrm{Ca}^{2+}\right]$ with DTBHQ in the presence of calcium also promotes neurite outgrowth (Holliday et al., 1991), favoring the wave hypothesis.

During development, the decrease in incidence and frequency of spikes is likely to be due to elevation of action potential threshold, maturation of sodium-dependent action potentials, and suppression of calcium influx (Barish, 1986; Lockery and Spitzer, 1992). Reduction of release from stores may further restrict their production (Holliday et al., 1991). The developmental persistence of waves indicates that the mechanisms trig- gering them continue to act for an extended period. Both spikes and waves have distinctive amplitudes, durations, and frequencies. Breaking the code by which the pattern of calcium elevations specifies neuronal differentiation motivates future work.

\section{References}

Agoston DV, Eiden LE, Brenneman DF, (1991) Calcium-dependent regulation of the enkephalin phenotype by neuronal activity during early ontogeny. J Neurosci Res 28:140-148.

Albritton NL, Meyer T, Stryer L (1992) Range of messenger action of calcium ion and inositol 1,4,5-trisphosphate. Science 258:18121815.

Bading H, Ginty DD, Greenberg ME (1993) Regulation of gene expression in hippocampal neurons by distinct calcium signaling pathways. Science 260:181-186.

Barish ME (1991) Increases in intracellular calcium ion concentration during depolarization of cultured embryonic Xenopus spinal neurones. J Physiol (Lond) 444:545-565.

Bekkers JM, Stevens CF (1990) Presynaptic mechanism for long-term potentiation in the hippocampus. Nature 346:724-729.

Berridge MJ, Irvine RF (1989) Inositol phosphates and cell signaling. Nature 341:197-205.

Berridge MJ, Cobbold PH, Cuthbertson KSR (1988) Spatial and temporal aspects of cell signalling. Philos Trans R Soc Lond [Biol] 320: 325-343.

Bixby JL, Spitzer NC (1984a) Early differentiation of vertebrate spinal neurons in the absence of voltage-dependent $\mathrm{Ca}^{+}+$and $\mathrm{Na}^{+}$influx. Dev Biol 106:89-96.

Bixby JL, Spitzer NC (1984b) The appearance and development of neurotransmitter sensitivity in Xenopus embryonic spinal neurones in vitro. J Physiol (Lond) 353:143-155.

Chen C, Zhang J, Vincent JD, Israel JM (1990) Sodium and calcium currents in action potentials of rat somatotrophs: their possible functions in growth hormone secretion. Life Sci 46:983-989.

Cohan CS, Kater SB (1986) Suppression of neurite elongation and growth cone motility by electrical activity. Science $232: 1638-1640$.

Connor JA (1993) Intracellular calcium mobilization by inositol 1,4,5trisphosphate: intracellular movements and compartmentalization. Cell Calcium 14:185-200.

Constantine-Paton M, Cline HT, Debski E (1990) Patterned activity, synaptic convergence, and the NMDA receptor in developing visual pathways. Annu Rev Neurosci 13:129-154.

Cornell-Bell AH, Finkbeiner SM, Cooper MS, Smith SJ (1990) Glutamate induces calcium waves in cultured astrocytes: long-range glial signaling. Science 247:470-473.

Dash PK, Karl KA, Colicos MA, Prywes R, Kandel ER (1991) cAMP response element-binding protein is activated by $\mathrm{Ca}^{2+} /$ calmodulin as well as cAMP-dependent protein kinase. Proc Natl Acad Sci USA 88:5061-5065.

Desarmenien MG, Spitzer NC (1991) Determinant role of calcium and protein kinase $\mathrm{C}$ in development of the delayed rectifier potassium current in Xenopus spinal neurons. Neuron 7:797-805.

Desarmenien MG, Clendening B, Spitzer NC (1993) In vivo development of voltage-dependent ionic currents in embryonic Xenopus spinal neurons. J Neurosci 13:2575-2581.

Dupont G, Berridge MJ, Goldbeter A (1991) Signal-induced $\mathrm{Ca}^{2+}$ oscillations: properties of a model based on $\mathrm{Ca}^{2+}$-induced $\mathrm{Ca}^{2+}$ release. Cell Calcium 12:73-85.

Fields RD, Neale EA, Nelson PG (1990) Effects of patterned electrical activity on neurite outgrowth from mouse sensory neurons. J Neurosci 10:2950-2964.

Grumbacher-Reinert S, Nicholls J (1992) Influence of substrate on retraction of neurites following electrical activity of leech Retzius cells in culture. J Exp Biol 167:1-14.

Grynkiewicz G, Poenie M, Tsien RY (1985) A new generation of $\mathrm{Ca}^{2+}$ indicators with greatly improved fluorescence properties. J Biol Chem $260: 3440-3450$.

Gu X, Spitzer NC (1993a) Spontaneous $\mathrm{Ca}^{2+}$ spikes and waves in cmbryonic Xenopus spinal neurons in vitro and in vivo. Soc Neurosci Abstr 19:1111.

Gu X, Spitzer NC (1993b) Low threshold $\mathrm{Ca}^{2+}$ current and its role in spontaneous elevations of intracellular $\mathrm{Ca}^{2+}$ in developing Xenopus neurons. J Neurosci 13:4936-4948. 
Gu X, Olson E, Spitzer NC (1992) Patterns of spontaneous transient elevations of intracellular calcium in embryonic spinal neurons prior to neurite extension. Soc Neurosci Abstr 18:1287.

Guthrie PB, Segal M, Kater SB (1991) Independent regulation of calcium revealed by imaging dendritic spines. Nature 354:76-80.

Hayes BP, Roberts A (1973) Synaptic junction development in the spinal cord of an amphibian embryo: an electron microscope study. Z Zellforsch 137:251-269.

Henderson LP, Smith MA, Spitzer NC (1984) The absence of calcium blocks impulse-evoked release of acetylcholine but not de novo formation of functional neuromuscular synaptic contacts in culture. $\mathrm{J}$ Neurosci 4:3140-3150.

Hernandez-Cruz A, Sala F, Adams PR (1990) Subcellular calcium transients visualized by confocal microscopy in a voltage-clamped vertebrate neuron. Science 247:858-862.

Holliday J, Spitzer NC (1990) Spontaneous calcium influx and its roles in differentiation of spinal neurons in culture. Dev Biol 141:13 23.

Holliday J, Spitzer NC (1991) Calcium channels in the regulation of cell growth, cell development and cellular interactions. In: The calcium channel: properties, function, regulation and clinical relevance (Hurwitz L, Partridge LD, Leach JK, eds), pp 137-155. Boca Raton: CRC.

Holliday J, Spitzer NC (1993) Calcium regulates neuronal differentiation both directly and via co-cultured myocytes. J Neurobiol 24: 506-514.

Holliday J, Adams RJ, Sejnowski TJ, Spitzer NC (1991) Calciuminduced release of calcium regulates differentiation of spinal neurons. Neuron 7:787-796.

Hoth M, Penner R (1992) Depletion of intracellular calcium stores activates a calcium current in mast cells. Nature 355:353-355.

Jaffe DB, Johnston D, Lasser-Ross N, Lisman JE, Miyakawa H, Ross WN (1992) The spread of $\mathrm{Na}^{+}$spikes determines the pattern of dendritic $\mathrm{Ca}^{2+}$ entry into hippocampal neurons. Nature 357:244-246.

Kao JP, Harootunian AT, Tsien RY (1989) Photochemically generated cytosolic calcium pulses and their detection by fluo-3. J Biol Chem 264:8179-8184.

Komuro H, Rakic P (1992) Selective role of N-type calcium channels in neuronal migration. Science 257:806-809.

Komuro H, Rakic P (1993) Modulation of neuronal migration by NMDA receptors. Science 260:95-97.

Lane JW, McBride DW Jr, Hamill OP (1991) Amiloride block of the mechanosensitive cation channel in Xenopus oocytes. J Physiol (Lond) 441:347-366

Lerea LS, McNamara JO (1993) Ionotropic glutamate receptor subtypes activate c-fos transcription by distinct calcium-requiring intracellular signaling pathways. Neuron 10:31-41.

Lev-Ram V, Miyakawa H, Lasser-Ross N, Ross WN (1992) Calcium transients in cerebellar Purkinje neurons evoked by intracellular stimulation. J Neurophysiol 68:1167-1177.

Lockery SR, Spitzer NC (1992) Reconstruction of action potential development from whole-ccll currents of differentiating spinal ncurons. J Neurosci 12:2268-2287.

Malinow R, Tsien RW (1990) Presynaptic enhancement shown by whole-cell recordings of long-term potentiation in hippocampal slices. Nature 346:177-180.

Mattson MP, Kater SB (1987) Calcium regulation of neurite elongation and growth cone motility. J Neurosci 7:4034-4043.

Miller RJ (1991) The control of neuronal $\mathrm{Ca}^{2+}$ homeostasis. Prog Neurobiol 37:255-285.
Müller W, Connor JA (1991) Dendritic spines as individual neuronal compartments for synaptic $\mathrm{Ca}^{2+}$ responses. Nature 354:73-76.

Nieuwkoop PD, Faber J (1967) Normal table of Xenopus laevis (Daudin): a systematic and chronological survey of the development of the fertilized egg till the end of metamorphosis, $2 \mathrm{~d}$ ed. Amsterdam: North Holland.

Nishi R, Berg DK (1981) Effects of high $\mathrm{K}^{+}$concentrations on the growth and development of ciliary ganglion neurons in cell culture. Dev Biol 87:301-307.

O'Donovan MJ, Sernagor E, Sholomenko G, Ho S, Anatal M, Yee W (1992) Development of spinal motor networks in the chick embryo. J Exp Zool 261:261-273.

O'Dowd DK, Ribera AB, Spitzer NC (1988) Development of voltagedependent calcium, sodium and potassium currents in Xenopus spinal neurons. J Neurosci 8:792-805.

Putney JW Jr (1990) Capacitative calcium entry revisited. Cell Calcium 11:611-624.

Randriamampita C, Tsien RY (1993) Emptying of intracellular $\mathrm{Ca}^{2+}$ stores releases a novel small messenger that stimulates $\mathrm{Ca}^{2+}$ influx Nature 364:809-814.

Ribera AB, Spitzer NC (1989) A critical period of transcription required for differentiation of the action potential of spinal neurons. Neuron 2:1055-1062

Rink TJ, Jacob R (1989) Calcium oscillations in non-excitable cells Trends Neurosci 12:43-46.

Shatz CJ (1990) Impulse activity and the patterning of connections during CNS development. Neuron 5:745-756.

Sheng HZ, Fields RD, Nelson PG (1993) Specific regulation of immediate early genes by patterned neuronal activity. J Neurosci Res 35:459-467.

Sheng M, McFadden G, Greenberg ME (1990) Membrane depolarization and calcium induce c-fos transcription via phosphorylation of transcription factor CREB. Neuron 4:571-582.

Sorimachi M, Morita Y, Nakamura H (1990a) Possible regulation of the cytosolic-free calcium concentration by $\mathrm{Na}^{+}$spikes in immature cerebellar Purkinje cells. Neurosci Lett 111:333-338.

Sorimachi M, Morita Y, Kuramoto K (1990b) Regulation of the cytosolic free calcium concentration by $\mathrm{Na}^{+}$spikes in immature cerebellar neurons with $N$-methyl-D-aspartate receptors. Brain Res 527: $155-158$

Spitzer NC (1982) Voltage and stage dependent uncoupling of RohonBeard neurones during embryonic development of Xenopus tadpoles. J Physiol (Lond) 330:145-162.

Spitzer NC, Lamborghini JE (1976) The development of the action potential mechanism of amphibian neurons isolated in culture. Proc Natl Acad Sci USA 73:1641-1645.

Spitzer NC, deBaca RC, Allen KA, Holliday J (1993) Calcium dependence of differentiation of GABA immunoreactivity in spinal neurons. J Comp Neurol 337:168-175.

Taylor JSH, Roberts A (1983) The early development of the primary sensory neurones in an amphibian embryo: a scanning electron microscope study. J Embryol Exp Morphol 75:49-66.

Walicke PA, Patterson PH (1981) On the role of $\mathrm{Ca}^{2+}$ in the transmitter choice made by cultured sympathetic neurons. J Neurosci 1:343-350.

Yuste R, Peinado A, Katz LC (1992) Neuronal domains in developing neocortex. Science 257:665-669.

Zweifach A, Lewis RS (1993) Mitogen-regulated $\mathrm{Ca}^{2+}$ current of T lymphocytes is activated by depletion of intracellular $\mathrm{Ca}^{2+}$ stores. Proc Natl Acad Sci USA 90:6295-6299. 